\title{
The effect of powder type on the setting time and self compactability of mortar
}

\author{
O.R. Khaleel, H. Abdul Razak
}

Self compacting concrete (SCC) is a type of concrete with unique properties, where it has the ability to flow under its own weight and fill congested areas without bleeding or segregation and without the need for vibration. There are three important factors which must be considered to produce SCC namely high flowability or deformability, controlled viscosity of cement pastes to avoid the risk of segregation or bleeding, and the coarse aggregate content for achieving good passing ability [1]. The role of mortar which acts as a lubricant in SCC is crucial since it gives SCC its fluidity. When the coarse aggregate particles comes close to each other, the mortar in between will be exposed to normal stress as shown in Fig. 1, and a reduction in the shear rheology of the mortar will lead to segregation thus entrapping the coarse aggregate particles behind reinforcement bars [2]. Thus rheology of the mortar is significantly important and there should be a balance between flowability and viscosity. High flowability can be achieved by either using excess water or by utilizing a superplasticising admixture. However, the adding of more water would lead to segregation of the mix constituents and at the same time reducing strength.

Topçu and Bilir [3] reported that SCC can be produced by using both chemical and mineral admixtures. Khayat [4] stated that the addition of superplasticizer will give rise to a reduction of the yield of cement paste and viscosity. In addition high dosage of superplactisizer disperses the cement particles and releases the water confined between cement particles and as a consequence will increase the amount of free water in the cement paste system [1]. Okamura and Masahiro [1] deduced that for SCC, the following superplasticizer properties are necessary:

The dispersing action must be high for a low water/powder ratio.

Maintaining the dispersing action few hours after mixing process.

Burak et al. [5] deduced that the optimal replacement level of cementitious or inert powders depended on their physical and physico-chemical characteristics. The characteristics have a significant 
effect on the fresh paste properties which is governed by the

shape of particles, surface porosity, fineness fraction content, and

particle size distribution. Sometimes it is difficult to recognize

the effect of these factors since they occur in combination [5]. Furthermore,

there are some types of powder which can increase the

flowability of concrete. Ferraris et al. [6] recognized that particles

with spherical shape and least surface/volume ratio can provide

good fluidity of mixes by minimizing the inter-particle friction

making the particles easy to roll over each other. The spherical

shape would also give high packing density resulting in lower void

ratio and higher strength. Ozawa et al. [7] found that the partial

replacement of Portland cement with fly ash led to improve flowability

of the concrete. Siddique [8] deduced from a study that the

addition of fly ash to concrete improved slump, while at the same

time reduced the superplasticizer dosage required to get the same

slump flow when compared with Portland cement concrete

Justice [9] demonstrated that adding metakaolin with $5 \%$ and

$10 \%$ of cement weight required a high dosage of superplasticizer

to achieve the same workability as compared with the reference

mix. Ramachandran [10] found that adding of limestone filler to

concrete accelerated the hydration process of Portland cement particles, especially the $C_{3} S$ at early ages. Its reaction with $C_{3} A$ creates

calcium carboaluminate which forms on the surface of $\mathrm{C}_{3} \mathrm{~A}$. While

Ellerbrock and Spung [11] showed that when limestone powder

was added to cement, the packing density of cement particles increased.

Bonavetti and Rahhal [12] indicated that the limestone

acted as nucleation sites for calcium hydroxide

When concrete flows, high viscosity of the paste will prevent segregation occurring due to the difference with specific gravities

of constituent materials of concrete. The required viscosity can be achieved namely by either increasing the powder content in the mix, using viscosity modifying admixtures (VMA) or both. Due to the high cost of VMA, powder materials are becoming more commonly used and preferred [1]. Ferraris et al. [6] concluded that at a given yield stress and viscosity, the replacement of cement with fly ash led to a decrease in the superplasticizer dosage. There has been few research work on the use of kaolin as a powder material and one of them by Sahmaran [13] concluded that replacement of Portland cement with kaolin had an adverse effect on the workability. Brooks et al. [14] reported that there are many factors having a direct effect on the setting time of concrete which includes $w / p$ ratio, cement content, fineness and composition, dosage and type of superplasticizer. Generally there is agreement that both fly ash and GGBFS cause retardation of setting time of concrete with higher replacement level leading to greater retardation. 
The objectives of this investigation are to study the effect of superplasticizer dosage on the flowability of mortar and establishing the saturation dosage for the formulated mixes, the effect of powder on the stability of mixes and the combined effect of superplasticizer and powder to achieve self compactability.

Experimental work

Materials

Three types of powder material were used in this study namely Type 1 ordinary Portland cement, fly ash and kaolin. The chemical and physical properties of these materials are given in Table 1. The particle size distribution of the powder materials are shown in Fig. 2. A modified polycarboxylate superplasticising admixture with specific gravity of $1.05 \%$ and $30 \%$ water reducer content was used. The mix constituents included silica sand with a fineness modulus of 2.4 , water absorption of $0.35 \%$ and specific gravity of 2.64. The grading of the sand is shown in Fig. 3 .

Mix proportion

The mix design adopted for this study was based on the guidelines given by EFNARC [15]. The water to powder ratio of 0.32 by weight was determined so that this ratio would give the minimum water requirement for the cement particles, to allow the cement paste to initiate flow. The optimum superplasticizer dosage was determined from the results of the mini slump flow cone of cement paste mixes as shown in Fig. 4. The mix proportions of the mortar mixes were formulated from the concrete mix proportion as given in Table 2. Thirty-three mortar mixes were prepared to study the effect of superplasticizer dosage and replacement of cement and sand with fly ash and metakaolin as pozzolans, while limestone powder and kaolin as fillers, respectively. Four replacement levels were considered, i.e. $5 \%$, $10 \%, 15 \%$, and $20 \%$ by weight of the cement and sand.

Mixing and testing

The mixing of the constituents of the mortar was carried out using a bowl mixer. Firstly fine aggregate was added, followed by cement and the powder material, and dry mixed for $2 \mathrm{~min}$. Subsequently two thirds of the total water content was slowly poured into the bowl while the mixer was still running. Finally the remaining water was added, which was premixed with the superplasticizer at the specified dosage determined from the trial mixes, and mixing was continued for a total time of $5 \mathrm{~min}$. The volume for each batch was $3 \mathrm{I}$. After mixing, the fluidity of the mixes was evaluated by using the mini slump flow and $V$-funnel box. These two tests were conducted in accordance to EFNARC guidelines [15]. Initial and final setting time of mortar was specified according to ASTM C403M-99 [16].

Full text available at :

http://ac.els-cdn.com/S0950061812002814/1-s2.0-S0950061812002814-main.pdf?_tid=157e0a36-781f11e3-9b03-00000aab0f6b\&acdnat $=1389156245$ 697e2e92da50d16433a1f4f4a980b8cb

http://www.sciencedirect.com/science/article/pii/S0950061812002814 